Review

\title{
ANRIL: Molecular Mechanisms and Implications in Human Health
}

\author{
Ada Congrains, Kei Kamide *, Mitsuru Ohishi and Hiromi Rakugi \\ Department of Geriatric Medicine and Nephrology, Osaka University Graduate School of Medicine, \\ 2-2 B6, Yamadaoka, Suita, Osaka 565-0871, Japan; E-Mails: ada@geriat.med.osaka-u.ac.jp (A.C.); \\ ohishi@geriat.med.osaka-u.ac.jp (M.O.); rakugi@geriat.med.osaka-u.ac.jp (H.R.) \\ * Author to whom correspondence should be addressed; E-Mail: kamide@geriat.med.osaka-u.ac.jp; \\ Tel.: +81-6-6879-3852; Fax: +81-6-6879-3859.
}

Received: 6 November 2012; in revised form: 28 December 2012 / Accepted: 4 January 2013 / Published: 10 January 2013

\begin{abstract}
ANRIL is a recently discovered long non-coding RNA encoded in the chromosome 9p21 region. This locus is a hotspot for disease-associated polymorphisms, and it has been consistently associated with cardiovascular disease, and more recently with several cancers, diabetes, glaucoma, endometriosis among other conditions. ANRIL has been shown to regulate its neighbor tumor suppressors CDKN2A/B by epigenetic mechanisms and thereby regulate cell proliferation and senescence. However, the clear role of ANRIL in the pathogenesis of these conditions is yet to be understood. Here, we review the recent findings on ANRIL molecular characterization and function, with a particular focus on its implications in human disease.
\end{abstract}

Keywords: ANRIL; CDKN2BAS; polycomb proteins; 9p21

\section{Introduction}

\subsection{The Chr9p21 Locus}

Recent findings from the genome-wide association studies (GWAS) have been pointing to novel disease-associated DNA regions, opening doors for new and more accurate targets for research and future therapies for several diseases. One of these new loci is the chromosome $9 \mathrm{p} 21$, which was highlighted as the strongest genetic susceptibility locus for cardiovascular disease (CVD) [1,2] and 
later linked to other conditions such as type 2 diabetes [2,3], Alzheimer disease [4], glaucoma [5,6], endometriosis [7] and periodontitis [8]. Interestingly, the CVD and diabetes-associated hot-spot lies in a region previously considered a gene desert, and overlaps the sequence of a newly discovered long non-coding RNA (lncRNA), ANRIL (antisense non coding RNA in the INK4 locus). Remarkably, variants in this region have also been associated with several cancers: leukemia [9], breast cancer [10], basal cell carcinoma [11], melanoma [12,13], pancreatic carcinoma [14], ovarian cancer [15], and glioma [16].

In the vicinity of the disease-associated haplotype block, three genes, $C D K N 2 A, C D K N 2 B$, and methyl-thioadenosine phosphorylase $(M T A P)$ appear as potential candidates to mediate the associations. $C D K N 2 A$ encodes for two distinct proteins, p16 and ARF, using alternative reading frames. CDKN2A/ARF and CDKN2B are known tumor suppressors and have well-established roles in cell proliferation, apoptosis, senescence and aging [17,18]. Deletion and inactivation of MTAP have also been connected to cancerogenesis $[19,20]$. It seemed plausible that the disease-associated SNPs would be regulating the expression of these genes. However, most of the disease-associated polymorphisms have been associated with the expression of ANRIL rather than $C D K N 2 A / B$ or $M T A P$ in several reports [21-23].

The 9p21 association with cardiovascular disease (CVD) presents an additional appeal besides being the strongest genetic factor identified by the genome wide association studies (GWAS). It is independent from most traditional risk factors [2], and therefore, it is likely to represent a component of the disease hitherto unknown and probably not targeted by current treatments.

Many of the polymorphisms in the 9p21 locus disrupt several predicted transcription factor binding sites [24] suggesting that the locus expression is regulated by numerous signaling pathways. Notably, some of these transcription factors are involved in key physiological processes such as inflammation, RAS response, and FOXO-Sirtuin-longevity signaling. ANRIL mediates the response to at least two of these signaling pathways: STAT1 [24] and RAS [25]. In addition, different disease-associated SNPs in the region have proven to modulate independently the expression of ANRIL and CDKN2A/B. In particular, the CVD-associated polymorphisms have been shown to regulate ANRIL expression in vitro [24] and also in human cohorts [21-23]. Seemingly, the polymorphisms act through independent mechanisms and some of them, at least, seem to be mediated by ANRIL.

\subsection{The Long Non Coding RNA in the Chromosome 9p21: ANRIL}

ANRIL is a long non-coding RNA (lncRNA) transcribed by RNA polymerase II [26], and spliced into multiple linear isoforms [27,28] including an ANRIL-MTAP fusion transcript [29]. Most of the splicing variants are polyadenylated; however, some circular non-polyadenylated variants have also been described [29]. Some of the splicing variants have been reported to be tissue-specific [28,29], suggesting their physiological relevance and underlining the complexity of its regulatory function.

ANRIL exons expression is detectable by RT-PCR, but their expression is low, as it is the case of other functional non-coding RNAs. Despite the numerous splicing variants that have been described, the characterization of the isoforms in different cell lines and tissues is still incomplete. However, the importance of the discrete long isoforms needs to be clarified; it is possible that the functionality of this non-coding RNA do not rely on the complete transcripts. In fact, analysis of next-generation 
RNA-sequencing results revealed a disparity in abundance between ANRIL exons [29]. Moreover, short non-coding RNAs forming hair-pin structures are already shown to be expressed from Polycomb-repressed loci and have a role in their repression in cis [30]. There seem not to be a simple motif or conserved structure in long non coding RNAs (lncRNAs) that is universally recognized by Polycomb proteins; however, there is evidence of structural patterns [31,32] and, in some cases stem-loop structures that preferentially bind these chromatin modifying proteins. An example of the requirement of such a structure is RepA which contains a conserved stem-loop structure generated by Xist transcript which is sufficient to recruit PRC2 in vivo [33,34]. Partial ANRIL transcripts carrying these structural patterns could be acting as independent regulatory molecules, rather than one or few long transcripts.

Interestingly, the central exons (Exon 4 to 12) of ANRIL seem to be the least abundant [29]. Those middle exons form rare circular isoforms whose expression is associated with the CVD-risk alleles [29]. Although the function of these circular variants of ANRIL is yet to be clarified, there is already evidence suggesting the importance of circular antisense transcripts [35].

\section{ANRIL, Polycomb Proteins and Epigenetic Regulation of the CDKN2A/B Locus}

Polycomb proteins are a group of proteins involved in transcriptional gene repression via two distinct histone modifications: trimethylation of lysine 27 on Histone 3 (K27H3) and monoubiquitination of histone H2A. They are key developmental regulators that play critical roles in differentiation, maintenance of cell identity [36] and cancerogenesis [37,38]. There have been several reports focused on their role on cancer development and progression; however, there are indications that the gene expression changes driven by histone modifying proteins control several aspects of human health [39-41].

Polycomb proteins work in multi-protein complexes, the Polycomb repressive complex 1 (PRC1) and 2 (PRC2). PRC2 is involved in the initiation of silencing by catalyzing the methylation of lysine 27 on Histone 3 (K27H3). PRC2 contains three subunits EED, SUZ12 and the methyltransferase EZH1/2. The PRC1 complex is involved in the maintenance of silencing of the target genes. PRC1 comprises BMI1, $\mathrm{mPh} 1 / 2$, a Chromobox $(\mathrm{CBX})$ and the $\mathrm{RINGA} / \mathrm{B}$, a ring finger protein with ubiquitin E3 ligase activity [42]. Several chromobox proteins have been described and each with a distinct pattern of binding in the chromatin [43], suggesting that the CBX unit confers specificity to the complex. Particularly, CBX7 has an important role in cellular life span [44] and is directly involved in the regulation of several genes frequently silenced in cancer [37]. Polycomb repressive complexes are critical in the epigenetic regulation of the $\mathrm{CDKN} 2 \mathrm{~A} / \mathrm{B}$ locus (reviewed in reference [45]). Moreover, histone modifications caused by Polycomb proteins occur in coordination with other epigenetic mechanisms. Polycomb proteins CBX7 and EZH2 interact with DNA methyltransferase DNMT3B and the activity of chromatin remodelers have shown to influence PRCs occupancy in the CDKN2A/B locus [45].

The association between long non-coding RNAs (lncRNAs) and polycomb ( $\mathrm{Pc}$ ) proteins to induce silencing is emerging as a common mechanism of epigenetic regulation. Other well documented examples of this kind of interaction are: Hotair [46], Kcnq1ot1 [47] and RepA [34], which have been reported to associate with polycomb proteins, acting as cofactors necessary for the polycomb proteins to silence their target loci. Growing evidence suggests that a large proportion of lncRNAs bind chromatin modifying proteins to alter expression patterns in different cell types [48]. 
ANRIL has been shown to specifically bind two polycomb proteins: CBX7 (PRC1) and SUZ12 (PRC2) $[25,26,42]$, to regulate histone modification in the $C D K N 2 A / B$ locus. Competitive inhibition of ANRIL transcript by expression of an antisense sequence impairs CBX7-mediated repression of the CDKN2A locus and causes a concomitant shortening of cellular life span [26] in human fibroblasts. Yap et al. also identified several RNA loop structures formed by ANRIL transcript, which specifically bind CBX7, and at least one of them participate in CBX7 recognition of histone methylated lysine (H3K27). CBX7 recognition of $\mathrm{H} 3 \mathrm{~K} 27$ is required for the mono-ubiquitination of Histone 2A in lysine 119 (H2A-K119) which in turn results in the maintenance of repression in the locus [26]. Intriguingly, ANRIL depletion caused the up-regulation of $C D K N 2 B$ but not $C D K N 2 A / A R F$ in another fetal fibroblast cell line [25]. This study demonstrated that ANRIL binds SUZ12 (component of Polycomb Repressive Complex 2) and influence cellular proliferation via regulation of CDKN2B.

The over-expression of an ANRIL splicing variant in Hela, causes the down-regulation of several genes involved in important chromatin architecture remodeling mechanisms [49]. Remarkably, one of the most down-regulated genes was co-activator p300 (also known as EP300) which is a transcriptional co-factor with histone acetyl-transferase activity [50]. P300 has numerous gene targets and localizes at enhancer sequences where it is involved in cell-type-specific gene expression determination [51]. Co-activator P300 has histone acetyltransferase activity, activates several loci related with senescence [52] and its patterns of occupancy change with aging [53]. Other genes suppressed by ANRIL over-expression have been previously linked to histone modification [54-56].

The deletion of the chromosome 9p21 orthologous region in mice caused a severe reduction of expression of $C D K N 2 A / B$, particularly in aortic and cardiac tissues [57]. This is consistent with the presence of multiple regulatory sequences identified in the CAD risk interval [24]. The deleted orthologous interval encompasses the region that in humans encodes for the last exons of ANRIL [58]. The mice $70 \mathrm{~kb}$ interval, orthologous to the human $58 \mathrm{~kb}$ coronary artery disease (CAD) risk region contains part of an antisense non-coding RNA, AK148321, as well as other annotated transcripts; however, there is no homology between ANRIL and the antisense transcripts identified in mice. Moreover, the effect of the deletion reported by Visel et al. seems inconsistent with the inhibitory effect of ANRIL upon CDKN2A and CDKN2B reported by several groups [25,26]. ANRIL has been proposed to be required for the recruitment of polycomb proteins and consequent repression of the $C D K N 2 A / B$ locus. In this sense, a similar role of the antisense transcript in mice seems unlikely. It seems more plausible that the reduced expression of $C D K N 2 A / B$ observed by Visel et al. comes as a result of the deletion of important regulatory sequences rather than the regulatory effect of the deleted exons of the AK148321 transcript. Furthermore, the regulation of the locus during senescence and oncogenic stimuli is intrinsically different in human and mice $[59,60]$, which difficult to extrapolate these results into the human locus. Further study is required to investigate the role of this transcript in the regulation of the $C D K N 2 A / B$ locus in mice.

More interestingly, the targeted deletion of the orthologous CAD-risk interval effect upon $C D K N 2 A / B$ in mice proved to be allele specific [57], suggesting that the action of the human transcript, ANRIL, could depend on its tethering to the chromosome where it is encoded. However, there is experimental evidence demonstrating ANRIL is able to silence CDKN2B promoter in trans, although less effectively than in cis [61]. 
Long non-coding RNAs are able to repress and activate gene expression via several mechanisms, and both, cis- and trans-acting long non-coding RNAs have been reported [62]. ANRIL has a soundly established role recruiting polycomb proteins in cis. However, the fact that ANRIL over-expression is able to induce histone modification in a distant CDKN2B promoter (acting in trans) [61], suggests that the local transcription of ANRIL is not indispensible for at least some of its regulatory function. The tantalizing possibility of a trans-acting ANRIL also highlights the necessity of comprehensive genome-wide approaches to unveil possible distant targets of this non-coding RNA.

Remarkably, ANRIL over-expression also induced DNA hyper-methylation of the locus in differentiated cells [61]. Although, evidence suggests a common role of non-coding RNAs precluding DNA methylation of their neighboring $\mathrm{CpG}$ islands, non-coding transcripts originated in the promoter of ribosomal RNA genes represent an example of non-coding RNAs inducing hyper-methylation in cis [62]. Furthermore, CBX7 is known to complex with DNA methyltransferase enzymes and therefore participates in DNA methylation of several loci involved in cancer [37], raising the question whether CBX7-ANRIL complex might also be mediating the effect on DNA methylation reported by Yu et al. [61].

ANRIL over-expression caused predominantly suppression of gene expression in HELA [49], and this is compatible with ANRIL being required by polycomb proteins to repress gene expression. However, there were some few genes up-regulated by ANRIL over-expression in this study. The gene up-regulated the most was RREBI (Ras responsive element binding protein) [49], a transcription factor that binds to RAS-responsive elements of gene promoters. Remarkably, there is a predicted binding site for RREB1 in the 9p21 locus, which is disrupted by one of the disease-associated SNPs (rs564398). Moreover, ANRIL expression is inhibited by RAS [25], possibly through RREB1. It seems plausible that RAS induces RREB1 activity to bind the responsive element within ANRIL locus and therefore inhibit its expression; ANRIL depletion, in turn, impairs repression of $C D K N 2 B$ with the consequent up-regulation of $C D K N 2 B$. These connections suggest a regulatory feedback between ANRIL and the RAS signaling pathway, strongly associated with cancerogenesis. This is a single example of the complexity of the regulatory landscape of the 9p21 locus and the possible implication of ANRIL in mediating the associations detected in the region. Furthermore, the existence of genes up- and down-regulated by ANRIL $[49,63]$ that do not seem downstream to $C D K N 2 A / B$ is suggesting a wider regulatory panorama for this non-coding RNA.

\section{ANRIL Expression in Disease}

ANRIL is over-expressed in leukemia patients leukocytes compared with normal controls, while $C D K N 2 B$ showed the opposite pattern of expression [61]. Remarkably, GWASs have detected a risk allele for acute lymphoblastic leukemia in the first exon of $C D K N 2 A$ [9], coinciding with the promoter region of ANRIL. ANRIL is also up-regulated in prostate cancer tissues in comparison with normal epithelial cells, accompanied by down-regulation of $C D K N 2 A$ [26].

In vitro, ANRIL depletion has been associated with reduced proliferation, suggesting a pro-cancerogenic role of the transcript. This view is also supported by the up-regulation of ANRIL observed in leukemia [9], prostate cancer tissues [26] and in the risk allele carriers for basal cell carcinoma (BCC) and glioma [23]. However, the $\mathrm{T}$ allele of the polymorphism rs2151280 was correlated with an increased number of plexiform neurofibromas and also with reduced ANRIL 
expression in patients suffering from a tumor predisposition syndrome [64]. In addition, a melanoma associated variant rs1011970-T was also associated with the reduction of ANRIL expression [23]. ANRIL exons show different expression levels and these studies target different regions of ANRIL for the expression quantification, complicating the interpretation of these correlations, see Table 1.

Table 1. Disease-associated SNPs correlated with ANRIL expression.

\begin{tabular}{|c|c|c|}
\hline SNP & Disease association & Reported effect on ANRIL expression \\
\hline rs564398-A & $\begin{array}{l}\text { Risk allele for diabetes and } \\
\text { atherosclerotic stroke [65] }\end{array}$ & $\begin{array}{l}\text { Reduced ANRIL expression (exons } 1-2 \text { ). Twice } \\
\text { reported to exert the strongest influence in ANRIL } \\
\text { expression in peripheral blood }[21,23]\end{array}$ \\
\hline rs1063192-C & $\begin{array}{l}\text { Risk for glioma [16] and open angle } \\
\text { glaucoma [6] }\end{array}$ & Increased ANRIL expression (exons 1-2) [21,23] \\
\hline rs1011970-T & Melanoma [13] & Reduced expression of ANRIL (exons 1-2) [23] \\
\hline rs2151280-T & $\begin{array}{l}\text { Risk allele for plexiform } \\
\text { neurofibroma development [64] and } \\
\text { protective allele for BCC [11] }\end{array}$ & Reduced expression of ANRIL (exons 15-16) [64] \\
\hline rs3731217-G & $\begin{array}{l}\text { Risk allele for Acute lymphoblastic } \\
\text { leukemia [9] }\end{array}$ & Reduced expression of ANRIL (exons 17-18) [21] \\
\hline rs496892-G & $\begin{array}{l}\text { Risk for atherosclerotic stroke [65] } \\
\text { and periodontitis }\end{array}$ & Reduced ANRIL expression (exons 1-2) [21,23] \\
\hline rs $10757278-\mathrm{G}$ & Lead SNP for CAD risk [66] & $\begin{array}{l}\text { Increased ANRIL variant EU741058 expression } \\
\text { (exons } 1-5 \text { of the long transcript) [22], but reduced } \\
\text { expression of ANRIL exons } 1-2 \text { [23]. }\end{array}$ \\
\hline rs3731257-G & Risk allele for ovarian cancer [15] & Increased expression of ANRIL (exons 1-2) [23] \\
\hline rs10811661-T & Risk allele for diabetes [2] & Reduced ANRIL expression (exons 1-2) [23] \\
\hline
\end{tabular}

Exon numbers are based on the 19 exon transcript.

Pro-oncogenic RAS inhibits ANRIL expression and activates CDKN2B [25]. Interestingly, one of the SNPs most strongly correlated with ANRIL expression, rs564398, [21,23] is predicted to disrupt "Ras responsive element binding protein 1" (RREB1) binding site in the 9p21 locus [24]. RAS oncogenes have a well-documented role in cancer pathophysiology [67], but RAS also participates in atherosclerosis progression, promoting vascular senescence and inducing pro-inflammatory cytokines expression [68].

Additionally, the silencing of ANRIL reduces proliferation in fibroblasts [26] and vascular smooth muscle cells [21]. This reduced proliferation might be the result of premature senescence, an important mechanism to prevent tumorogenesis but also implicated in endothelial dysfunction [69] and inducing a pro-inflammatory phenotype in vascular smooth muscle cell [68].

The presence of multiple enhancers [24] and CCCTC-binding factor (CTCF) binding sites [24,70] in the 9p21 region suggests that its transcripts, CDKN2A/B/ANRIL, are subject to complex temporal and tissue-specific regulation. The cell-type specific effect of the transcription factor STAT1 upon ANRIL expression represents an illustration of the complex regulatory panorama underlying the chr9p21 associations. The pro-inflammatory cytokine, Interferon gamma, stimulates STAT1 activity and binding to a site harboring two risk variants for CAD in the 9p21 locus. The binding of STAT1 induces the expression of ANRIL, and represses CDKN2B in endothelial cells. However, the silencing 
of STAT1 in the non-risk-haplotype-carrier Lymphoblastoid cells (LCLs) induces expression of ANRIL, suggesting that the binding of STAT1 reduces expression of ANRIL in LCLs [24].

ANRIL expression was also up-regulated in gingival epithelial cells and gingival fibroblasts during bacterial infection, which supports the role of ANRIL in inflammatory response [8]. In this study the increased expression of ANRIL was accompanied by reduction in CDKN2A expression, and no effect on CDKN2B expression.

Cardiovascular disease (CVD) risk-alleles in the 9p21 region have been associated with ANRIL expression. However, the CVD-risk alleles have been associated with both, increased [22] and reduced expression of ANRIL [21,23]. Holdt et al. presented a meticulous analysis of 4 CVD-associated SNPs and their role in the expression of some of ANRIL splicing variants and CDKN2A/B in a large patient sample. In this study, they elegantly associated an increased expression of ANRIL with the risk alleles and atherosclerosis severity. However, the analysis of two other smaller volunteer samples: 487 [23] and 57 [21] individuals, evaluating different exons, correlated the risk alleles with a reduction of ANRIL expression. Diabetes-associated risk variants (rs10811661-T and rs2383208-A) were associated with a down-regulation of ANRIL expression [23].

This locus has been focus of particular interest throughout the last decades because of its connection with cancer [71], aging [17,72] and more recently its role in stem cell reprograming [73]. However, there are some unclear points in the role of $\mathrm{CDKN} 2 \mathrm{~A} / \mathrm{B}$ in human health and aging. Although, $\mathrm{CDKN} 2 \mathrm{AB} / \mathrm{ARF}$ locus overexpression seems to have a positive over-all effect in life span in mice [17], there is some contradictory evidence regarding the role of these tumor suppressors in disease. CDKN2A/B locus is silenced in young healthy cells and its expression is stimulated by age and oncogenic insults [71]. This increase in expression (particularly of CDKN2A) is associated with the impaired regenerative potential of several tissues observed during aging [74,75]; however, $\mathrm{CDKN} 2 \mathrm{~A} / \mathrm{B}$ is silenced or deleted in a wide-range of human cancers [71], suggesting it has a key role preventing cancerogenesis. Certainly, the regulation of this locus may be at a key cross point between aging, healthy regenerative proliferation and tumorogenesis. The idea that this non-coding RNA might shed new light on the mechanisms regulating this locus is enticing.

\section{Conclusions and Discussion}

Non-coding RNAs are long known to mediate gene expression regulation by a variety of mechanisms [76]. The literature is dominated by reports of small non-coding RNAs, such as microRNAs; however, long non-coding RNAs are arising as important regulators of gene expression. The long non-coding RNA in INK4 locus, ANRIL, is encoded in a genetic region highlighted for its connection with several human diseases and the material reviewed herein suggests that ANRIL has an important role in mediating the associations detected in the 9p21 locus.

It seems clear at this point that ANRIL is involved in at least three different mechanisms of epigenetic regulation: initiation of long term repression of CDKN2B locus by complexing SUZ12 in the polycomb repressive complex 2 (PRC2) [25], maintenance of chromatin silencing of the CDKN2A/B locus through interaction with CBX7 in the Polycomb repressive complex 1 (PRC1) [26], and also has been shown to alter DNA methylation of the locus in differentiated cells [61]. However, these functions are apparently not universal, but instead dependent on cell type and sensitive to 
physiological changes of the cell, such as senescence or differentiation. Our group has reported some effects of ANRIL over CDKN2A expression [21] and other atherosclerosis-related genes [63] in vascular smooth muscle cells (VSMC) that are not explained by the polycomb-repression mechanism. It is not clear whether these regulatory effects are mediated by other chromatin-modifying proteins, by the ANRIL circular isoforms, DNA methylation or other novel mechanism (Figure 1).

Figure 1. (A) Chr9p21 region is rich in regulatory elements and several transcription factor (TF) binding sites have been predicted along its sequence. These transcription factors are activated in response to external factors and signaling pathways, in a cell-type specific manner. TF binding possibly activates or represses the expression of ANRIL. Polycomb protein complexes 1 and 2 (PRC1 and PRC2), have RNA binding domains in their subunits CBX7 and SUZ12 respectively. ANRIL binds SUZ12 subunit of PRC2 to induce methylation of histone 3 in the lysine 27 (H3K27) and consequent silencing of the CDKN2A/B locus. ANRIL binds CBX7 in PRC1 which allows the recognition of H3K27 necessary for the monoubiquitination at histone 2A at lysine 119 (H2AK119) and maintenance of silencing. Therefore, ANRIL modulation impacts in the repressing ability of Polycomb proteins, inducing or inhibiting expression of CDKN2A/B and possibly other distant loci by histone modification. The disease-associated alleles might impair TF binding and response to different stimuli, alter ANRIL/CDKN2A/B expression (and possibly other loci) and contribute to disease development and progression; (B) Diagram showing the transcripts encoded in the 9p21 locus. ANRIL is represented in the diagram as the longest variant reported (CDKN2BAS-1), but several other alternative isoforms have been described.

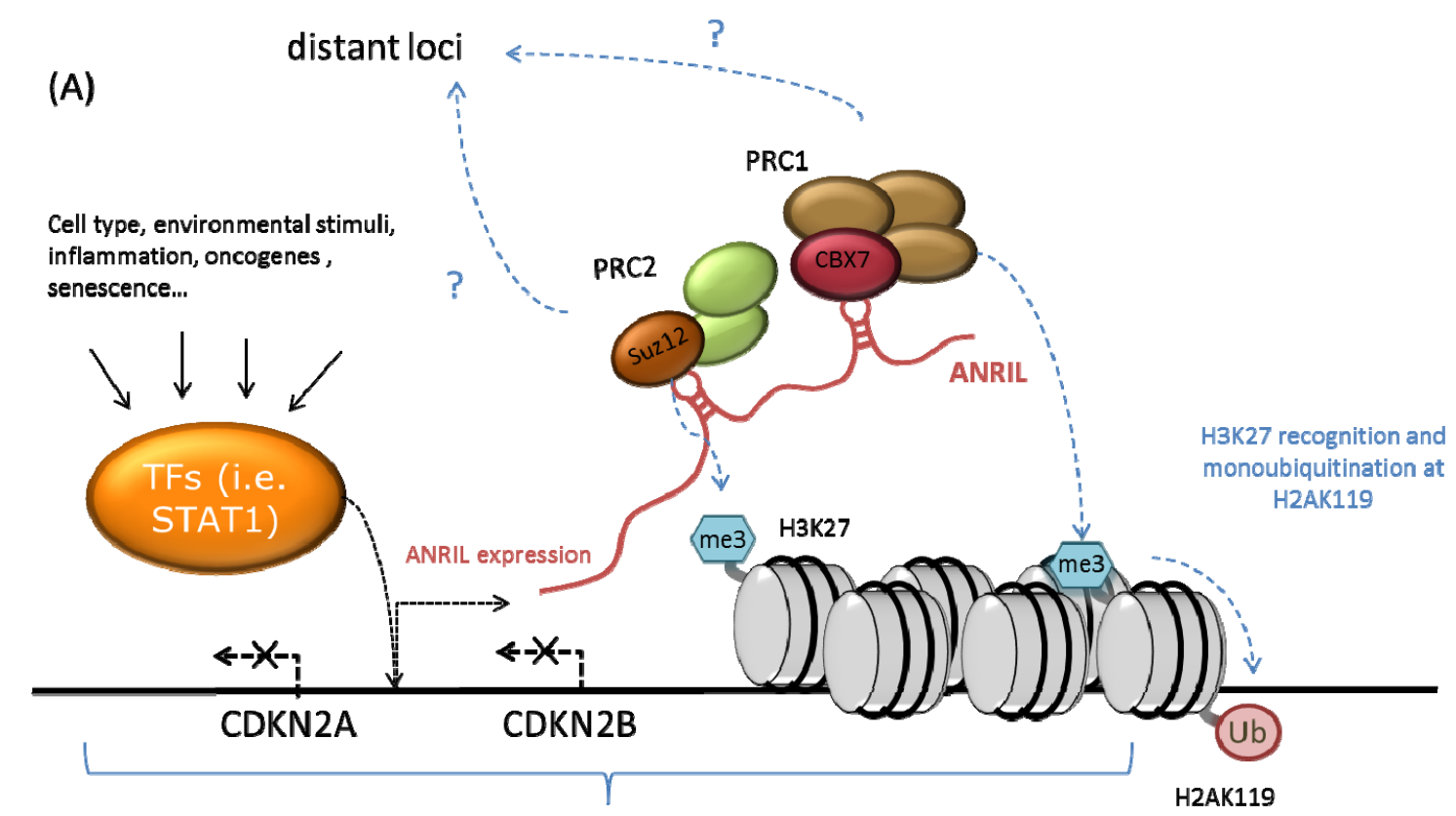

Multiple transcription factor binding sites

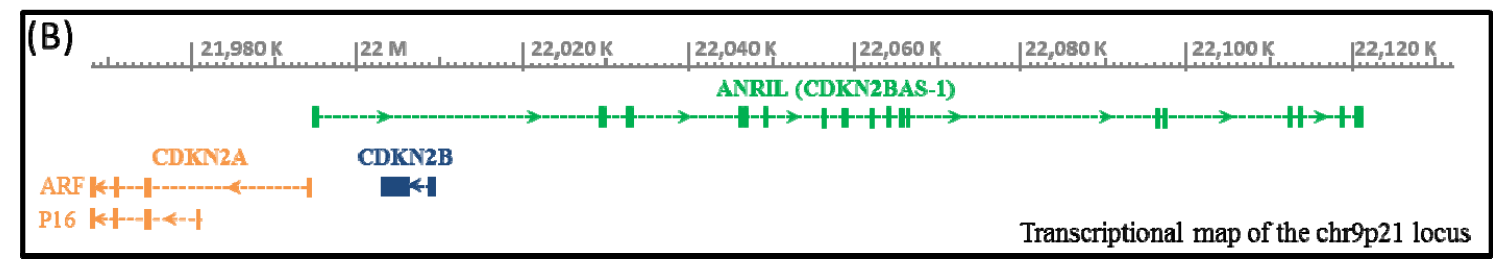


Both Kotake et al. [25] and Yap et al. [26] presented strong experimental evidence demonstrating a regulatory role of ANRIL upon $\mathrm{CDKN} 2 \mathrm{~A} / \mathrm{B}$ through polycomb proteins; however, the role of these polycomb proteins exceeds the CDKN2A/B locus, and they have a well-established participation in remodeling global expression patterns [77,78]. Furthermore, metastasis-associated lncRNA, Hotair, which also associates with PRC2, is involved in the recruitment of SUZ12 and EHZ2 to more than 800 genes [38]. Thus, it would not come as a surprise if ANRIL also is involved in the regulation of several distant loci. The effect of ANRIL splicing variants upon genome-wide chromatin modification changes has not been investigated. However, there is already evidence suggesting that ANRIL has effects over loci other than CDKN2A/B $[49,63]$.

In the light of the new findings regarding ANRIL function, it is appealing to hypothesize that the 9p21 association might be explained by ANRIL-driven regulation of CDKN2A/B and the consequent changes in cellular proliferation. Unquestionably, there is an altered cellular proliferation component in almost all the diseases associated with the locus; however further investigation is required to clearly unravel the role of these genes in the development of these pathologies.

CDKN2A/B locus is certainly associated with cancerogenesis but the connection of this locus with atherosclerosis is less clear. A recent report unveiled a pro-atherogenic role of CDKN2A in vivo in mice and a more significant protective role of MTAP (a more distant neighbor of the 9p21 regulatory region) [79]. The relevance of MTAP and the MTAP-ANRIL fusion transcript needs to be investigated to clarify their role in atherogenesis.

Another issue that remains to be clarified is the function of the circular isoforms of ANRIL. A natural antisense transcript forming a circular structure has been shown to be target of nuclear microRNAs and appear to participate in a recently discovered regulatory mechanism in which the circular isoform stabilizes the sense transcript rather than represses it [35]. The possibility of ANRIL circular variants playing a similar role in gene regulation is intriguing, and is definitely worth further analysis.

Clearly, there are several points that remain elusive regarding ANRIL function and its connection to the diseases associated with the 9p21 locus. It is clear that the regulatory mechanisms operating in the region are tissue specific, however, the effects of the polymorphisms over ANRIL expression and the regulatory mechanisms of ANRIL have only been evaluated in few tissues. Determining cell-type specific effects in tissues relevant to atherosclerosis, diabetes and other conditions associated with the locus requires further investigation. The function of ANRIL activating polycomb proteins and repressing the CDKN2A/B locus has been elegantly demonstrated [25,26]; however, its role in global histone remodeling has not been addressed. Finally, ANRIL forms several hair-pin structures along its exons, but the properties of the different regions of the ANRIL transcript and their affinity to bind polycomb proteins has remained unexplored.

All this evidence supports the idea that ANRIL is a key regulatory molecule mediating human disease at different levels and cellular settings. ANRIL is a probable mediator of the Chr9p21 associations and a particularly interesting target for new therapies for a wide range of human diseases. 


\section{Acknowledgements}

This study was supported in part by grants-in-aid from the Program for Promotion of Fundamental Studies in National Institute of Biomedical Innovation of Japan (HR:22-2-5), the Ministry of Education, Culture, Sports, Science, and Technology of Japan (KK: 22510211).

\section{References}

1. The Wellcome Trust Case Control Consortium. Genome-wide association study of 14,000 cases of seven common diseases and 3000 shared controls. Nature 2007, 447, 661-678.

2. Broadbent, H.M.; Peden, J.F.; Lorkowski, S.; Goel, A.; Ongen, H.; Green, F.; Clarke, R.; Collins, R.; Franzosi, M.G.; Tognoni, G.; et al. Susceptibility to coronary artery disease and diabetes is encoded by distinct, tightly linked, SNPs in the ANRIL locus on chromosome 9p. Hum. Mol. Genet. 2008, 17, 806-814.

3. Cugino, D.; Gianfagna, F.; Santimone, I.; de Gaetano, G.; Donati, M.B.; Iacoviello, L.; di Castelnuovo, A. Type 2 diabetes and polymorphisms on chromosome 9p21: A meta-analysis. Nutr. Metab. Cardiovasc. Dis. 2012, 22, 619-625.

4. Emanuele, E.; Lista, S.; Ghidoni, R.; Binetti, G.; Cereda, C.; Benussi, L.; Maletta, R.; Bruni, A.C.; Politi, P. Chromosome 9p21.3 genotype is associated with vascular dementia and Alzheimer's disease. Neurobiol. Aging 2011, 32, 1231-1235.

5. Burdon, K.P.; Macgregor, S.; Hewitt, A.W.; Sharma, S.; Chidlow, G.; Mills, R.A.; Danoy, P.; Casson, R.; Viswanathan, A.C.; Liu, J.Z. Genome-wide association study identifies susceptibility loci for open angle glaucoma at TMCO1 and CDKN2BAS1. Nat. Genet. 2011, 43, 574-578.

6. Ramdas, W.D.; van Koolwijk, L.M.; Lemij, H.G.; Pasutto, F.; Cree, A.J.; Thorleifsson, G.; Janssen, S.F.; Jacoline, T.B.; Amin, N.; Rivadeneira, F. Common genetic variants associated with open-angle glaucoma. Hum. Mol. Genet. 2011, 20, 2464-2471.

7. Uno, S.; Zembutsu, H.; Hirasawa, A.; Takahashi, A.; Kubo, M.; Akahane, T.; Aoki, D.; Kamatani, N.; Hirata, K.; Nakamura, Y. A genome-wide association study identifies genetic variants in the CDKN2BAS locus associated with endometriosis in Japanese. Nat. Genet. 2010, 42, 707-710.

8. Schaefer, A.S.; Richter, G.M.; Groessner-Schreiber, B.; Noack, B.; Nothnagel, M.; el Mokhtari, N.E.; Loos, B.G.; Jepsen, S.; Schreiber, S. Identification of a shared genetic susceptibility locus for coronary heart disease and periodontitis. PLoS Genet. 2009, 5, e1000378.

9. Sherborne, A.L.; Hosking, F.J.; Prasad, R.B.; Kumar, R.; Koehler, R.; Vijayakrishnan, J.; Papaemmanuil, E.; Bartram, C.R.; Stanulla, M.; Schrappe, M.; et al. Variation in CDKN2A at 9p21.3 influences childhood acute lymphoblastic leukemia risk. Nat. Genet. 2010, 42, 492-494.

10. Turnbull, C.; Ahmed, S.; Morrison, J.; Pernet, D.; Renwick, A.; Maranian, M.; Seal, S.; Ghoussaini, M.; Hines, S.; Healey, C.S.; et al. Genome-wide association study identifies five new breast cancer susceptibility loci. Nat. Genet. 2010, 42, 504-507.

11. Stacey, S.N.; Sulem, P.; Masson, G.; Gudjonsson, S.A.; Thorleifsson, G.; Jakobsdottir, M.; Sigurdsson, A.; Gudbjartsson, D.F.; Sigurgeirsson, B.; Benediktsdottir, K.R.; et al. New common variants affecting susceptibility to basal cell carcinoma. Nat. Genet. 2009, 41, 909-914. 
12. Kumar, R.; Smeds, J.; Berggren, P.; Straume, O.; Rozell, B.L.; Akslen, L.A.; Hemminki, K.A. A single nucleotide polymorphism in the $3^{\prime}$ untranslated region of the CDNK2A gene is common in sporadic primary melanomas but mutations in the CDKN2B, CDKN2C, CDK4 and P53 genes are rare. Int. J. Cancer 2001, 95, 388-393.

13. Yeh, I.; Bastian, B.C. Genome-wide associations studies for melanoma and nevi. Pigment Cell Melanoma Res. 2009, 22, 527-528.

14. Chen, J.; Li, D.; Wei, C.; Sen, S.; Killary, A.M.; Amos, C.I.; Evans, D.B.; Abbruzzese, J.L.; Frazier, M.L. Aurora-A and p16 polymorphisms contribute to an earlier age at diagnosis of pancreatic cancer in Caucasians. Clin. Cancer Res. 2007, 13, 3100-3104.

15. Gayther, S.A.; Song, H.; Ramus, S.J.; Kjaer, S.K.; Whittemore, A.S.; Quaye, L.; Tyrer, J.; Shadforth, D.; Hogdall, E.; Hogdall, C.; et al. Tagging single nucleotide polymorphisms in cell cycle control genes and susceptibility to invasive epithelial ovarian cancer. Cancer Res. 2007, 67, 3027-3035.

16. Rajaraman, P.; Melin, B.S.; Wang, Z.; McKean-Cowdin, R.; Michaud, D.S.; Wang, S.S.; Bondy, M.; Houlston, R.; Jenkins, R.B.; Wrensch, M.; et al. Genome-wide association study of glioma and meta-analysis. Hum. Genet. 2010, 131, 1877-1888.

17. Matheu, A.; Maraver, A.; Collado, M.; Garcia-Cao, I.; Cañamero, M.; Borras, C.; Flores, J.M.; Klatt, P.; Viña, J.; Serrano, M. Anti-aging activity of the Ink4/Arf locus. Aging Cell 2009, 8, 152-161.

18. Cánepa, E.T.; Scassa, M.E.; Ceruti, J.M.; Marazita, M.C.; Carcagno, A.L.; Sirkin, P.F.; Ogara, M.F. INK4 proteins, a family of mammalian CDK inhibitors with novel biological functions. IUBMB Life 2007, 59, 419-426.

19. Schmid, M.; Malicki, D.; Nobori, T.; Rosenbach, M.D.; Campbell, K.; Carson, D.A.; Carrera, C.J. Homozygous deletions of methylthioadenosine phosphorylase (MTAP) are more frequent than p16 non-small cell lung cancers (NSCLC). Oncogene 1998, 17, 2669-2675.

20. Hellerbrand, C.; Mühlbauer, M.; Wallner, S.; Schuierer, M.; Behrmann, I.; Bataille, F.; Weiss, T.; Schölmerich, J.; Bosserhoff, A.K. Promoter-hypermethylation is causing functional relevant downregulation of methylthioadenosine phosphorylase (MTAP) expression in hepatocellular carcinoma. Carcinogenesis 2006, 27, 64-72.

21. Congrains, A.; Kamide, K.; Oguro, R.; Yasuda, O.; Miyata, K.; Yamamoto, E.; Kawai, T.; Kusunoki, H.; Yamamoto, H.; Takeya, Y. et al. Genetic variants at the 9p21 locus contribute to atherosclerosis through modulation of ANRIL and CDKN2A/B. Atherosclerosis 2012, 220, 449-455.

22. Holdt, L.M.; Beutner, F.; Scholz, M.; Gielen, S.; Gäbel ,G.; Bergert, H.; Schuler, G.; Thiery, J.; Teupser, D. ANRIL expression is associated with atherosclerosis risk at chromosome 9p21. Arterioscler. Thromb. Vasc. Biol. 2010, 30, 620-627.

23. Cunnington, M.S.; Santibanez Koref, M.; Mayosi, B.M.; Burn, J.; Keavney, B. Chromosome 9p21 SNPs associated with multiple disease phenotypes correlate with ANRIL expression. PLoS Genet. 2010, 6, e1000899.

24. Harismendy, O.; Notani, D.; Song, X.; Rahim, N.G.; Tanasa, B.; Heintzman, N.; Ren, B.; Fu, X.D.; Topol, E.J.; Rosenfeld, M.G.; et al. 9p21 DNA variants associated with coronary artery disease impair interferon- $\gamma$ signalling response. Nature 2011, 470, 264-268. 
25. Kotake, Y.; Nakagawa, T.; Kitagawa, K.; Suzuki, S.; Liu, N.; Kitagawa, M.; Xiong, Y. Long non-coding RNA ANRIL is required for the PRC2 recruitment to and silencing of p15INK4B tumor suppressor gene. Oncogene 2011, 30, 1956-1962.

26. Yap, K.L.; Li S.; Muñoz-Cabello, A.M.; Raguz, S.; Zeng, L.; Mujtaba, S.; Gil, J.; Walsh, M.J.; Zhou, M.M. Molecular interplay of the noncoding RNA ANRIL and methylated histone H3 lysine 27 by polycomb CBX7 in transcriptional silencing of INK4a. Mol. Cell 2010, 38, 662-674.

27. Pasmant, E.; Laurendeau, I.; Héron, D.; Vidaud, M.; Vidaud, D.; Bièche, I. Characterization of a germ-line deletion. Including the entire INK4/ARF locus, in a melanoma-neural system tumor family identification of ANRIL, an antisense noncoding RNA whose expression coclusters with ARF. Cancer Res. 2007, 67, 3963-3969.

28. Folkersen, L.; Kyriakou, T.; Goel, A.; Peden, J.; Mälarstig, A.; Paulsson-Berne, G.; Hamsten, A.; Watkins, H.; Franco-Cereceda, A.; Gabrielsen, A.; et al. PROCARDIS consortia. Relationship between CAD risk genotype in the chromosome 9p21 locus and gene expression. Identification of eight new ANRIL splice variants. PLoS One 2009, 4, e7677.

29. Burd, C.E.; Jeck, W.R.; Liu, Y.; Sanoff, H.K.; Wang, Z.; Sharpless, N.E. Expression of linear and novel circular forms of an INK4/ARF-associated non-coding RNA correlates with atherosclerosis risk. PLoS Genet. 2010, 6, e1001233.

30. Kanhere, A.; Viiri, K.; Araújo, C.C.; Rasaiyaah, J.; Bouwman, R.D.; Whyte, W.A.; Pereira, C.F.; Brookes, E.; Walker, K.; Bell, G.W.; et al. Short RNAs are transcribed from repressed polycomb target genes and interact with polycomb repressive complex-2. Mol. Cell 2010, 38, 675-688.

31. Glazko, G.V.; Zybailov, B.L.; Rogozin, I.B. Computational prediction of polycomb-associated long non-coding RNAs. PLoS One 2012, 7, e44878.

32. Guil, S.; Soler, M.; Portela, A.; Carrère, J.; Fonalleras, E.; Gómez, A.; Villanueva, A.; Esteller, M. Intronic RNAs mediate EZH2 regulation of epigenetic targets. Nat. Struct. Mol. Biol. 2012, 19, 664-670.

33. Duszczyk, M.M.; Zanier, K.; Sattler, M. A NMR strategy to unambiguously distinguish nucleic acid hairpin and duplex conformations applied to a Xist RNA A-repeat. Nucleic Acids Res. 2008, 36, 7068-7077.

34. Zhao, J.; Sun, B.K.; Erwin, J.A.; Song, J.J.; Lee, J.T. Polycomb proteins targeted by a short repeat RNA to the mouse X chromosome. Science 2008, 322, 750-756.

35. Hansen, T.B.; Wiklund, E.D.; Bramsen, J.B.; Villadsen, S.B.; Statham, A.L.; Clark, S.J.; Kjems, J. miRNA-dependent gene silencing involving Ago2-mediated cleavage of a circular antisense RNA. EMBO J. 2011, 30, 4414-4422.

36. Orlando, V. Polycomb, epigenomes, and control of cell identity. Cell 2003, 112, 599-606.

37. Mohammad, H.P.; Cai, Y.; McGarvey, K.M.; Easwaran, H.; van Neste, L.; Ohm, J.E.; O’Hagan, H.M.; Baylin, S.B. Polycomb CBX7 promotes initiation of heritable repression of genes frequently silenced with cancer-specific DNA hypermethylation. Cancer Res. 2009, 69, 6322-6330.

38. Gupta, R.A.; Shah, N.; Wang, K.C.; Kim, J.; Horlings, H.M.; Wong, D.J.; Tsai, M.C.; Hung, T.; Argani, P.; Rinn, J.L.; et al. Long non-coding RNA HOTAIR reprograms chromatin state to promote cancer metastasis. Nature 2010, 464, 1071-1076. 
39. Ordovás, J.M.; Smith, C.E. Epigenetics and cardiovascular disease. Nat. Rev. Cardiol. 2010, 7, 510-519.

40. Koleganova, N.; Benz, K.; Piecha, G.; Ritz, E.; Amann, K. Renal, cardiovascular and metabolic effects of fetal programming. Nephrol. Dial. Transplant. 2012, 27, 3003-3007.

41. Okamura, M.; Inagaki, T.; Tanaka, T.; Sakai, J. Role of histone methylation and demethylation in adipogenesis and obesity. Organogenesis 2010, 6, 24-32.

42. Aguilo, F.; Zhou, M.M.; Walsh, M.J. Long noncoding RNA, polycomb, and the ghosts haunting INK4b-ARF-INK4a expression. Cancer Res. 2011, 71, 5365-5369.

43. Vincenz, C.; Kerppola, T.K. Different polycomb group CBX family proteins associate with distinct regions of chromatin using nonhomologous protein sequences. Proc. Natl. Acad. Sci. USA 2008, 105, 16572-16577.

44. Gil, J.; Bernard, D.; Martínez, D.; Beach, D. Polycomb CBX7 has a unifying role in cellular lifespan. Nat. Cell Biol. 2004, 6, 67-72.

45. Popov, N.; Gil, J. Epigenetic regulation of the INK4b-ARF-INK4a locus: In sickness and in health. Epigenetics 2010, 5, 685-690.

46. Tsai, M.C.; Manor, O.; Wan, Y.; Mosammaparast, N.; Wang, J.K.; Lan, F.; Shi, Y.; Segal, E.; Chang, H.Y. Long noncoding RNA as modular scaffold of histone modification complexes. Science 2010, 329, 689-693.

47. Pandey, R.R.; Mondal, T.; Mohammad, F.; Enroth, S.; Redrup, L.; Komorowski, J.; Nagano, T.; Mancini-Dinardo, D.; Kanduri, C. Kcnq1 ot1 antisense noncoding RNA mediates lineage-specific transcriptional silencing through chromatin-level regulation. Mol. Cell 2008, 32, 232-246.

48. Khalil, A.M.; Guttman, M.; Huarte, M.; Garber, M.; Raj, A.; Morales, D.R.; Thomas, K.; Presser, A.; Bernstein, B.E.; van Oudenaarden, A.; et al. Many human large intergenic noncoding RNAs associate with chromatin-modifying complexes and affect gene expression. Proc. Natl. Acad. Sci. USA 2009, 106, 11667-11672.

49. Sato, K.; Nakagawa, H.; Tajima, A.; Yoshida, K.; Inoue, I. ANRIL is implicated in the regulation of nucleus and potential transcriptional target of E2F1. Oncol. Rep. 2010, 24, 701-707.

50. Ghosh, A.K.; Varga, J. The transcriptional coactivator and acetyltransferase p300 in fibroblast biology and fibrosis. J. Cell Physiol. 2007, 213, 663-671.

51. Heintzman, N.D.; Hon, G.C.; Hawkins, R.D.; Kheradpour, P.; Stark, A.; Harp, L.F.; Ye, Z.; Lee, L.K.; Stuart, R.K.; Ching, C.W.; et al. Histone modifications at human enhancers reflect global cell-type-specific gene expression. Nature 2009, 459, 108-112.

52. Bandyopadhyay, D.; Okan, N.A.; Bales, E.; Nascimento, L.; Cole, P.A.; Medrano, E.E. Down-regulation of p300/CBP histone acetyltransferase activates a senescence checkpoint in human melanocytes. Cancer Res. 2002, 62, 6231-6239.

53. Li, Q.; Xiao, H.; Isobe K. Histone acetyltransferase activities of cAMP-regulated enhancer-binding protein and p300 in tissues of fetal, young, and old mice. J. Gerontol. A 2002, 57, B93-B98.

54. Ooi, L.; Wood, I.C. Chromatin crosstalk in development and disease: Lessons from REST. Nat. Rev. Genet. 2007, 8, 544-554.

55. Wolf, S.S.; Patchev, V.K.; Obendorf, M. A novel variant of the putative demethylase gene, s-JMJD1C, is a coactivator of the AR. Arch. Biochem. Biophys. 2007, 460, 56-66. 
56. Lluis, F.; Ombrato, L.; Pedone, E.; Pepe, S.; Merrill, B.J.; Cosma, M.P. T-cell factor 3 (Tcf3) deletion increases somatic cell reprogramming by inducing epigenome modifications. Proc. Natl. Acad. Sci. USA 2011, 108, 11912-11917.

57. Visel, A.; Zhu, Y.; May, D.; Afzal, V.; Gong, E.; Attanasio, C.; Blow, M.J.; Cohen, J.C.; Rubin, E.M.; Pennacchio, L.A. Targeted deletion of the 9p21 non-coding coronary artery disease risk interval in mice. Nature 2010, 464, 409-412.

58. Pasmant, E.; Sabbagh, A.; Vidaud, M.; Bièche, I. ANRIL, a long, noncoding RNA, is an unexpected major hotspot in GWAS. FASEB J. 2011, 25, 444-448.

59. Rangarajan, A.; Weinberg, R.A. Comparative biology of mouse versus human cells: Modeling human cancer in mice. Nat. Rev. Cancer 2003, 3, 952-959.

60. Wei, W.; Hemmer, R.M.; Sedivy, J.M. Role of p14ARF in replicative and induced senescence of human fibroblasts. Mol. Cell. Biol. 2001, 21, 6748-6757.

61. Yu, W.; Gius, D.; Onyango, P.; Muldoon-Jacobs, K.; Karp, J.; Feinberg, A.P.; Cui, H. Epigenetic silencing of tumour suppressor gene p15 by its antisense RNA. Nature 2008, 451, 202-206.

62. Guil, S.; Esteller, M. Cis-acting noncoding RNAs: Friends and foes. Nat. Struct. Mol. Biol. 2012, 19, 1068-1075.

63. Congrains, A.; Kamide, K.; Katsuya T.; Yasuda, O.; Oguro, R.; Yamamoto, K.; Ohishi, M.; Rakugi, H. CVD-associated non-coding RNA, ANRIL, modulates expression of atherogenic pathways in VSMC. Biochem. Biophys. Res. Commun. 2012, 419, 612-616.

64. Pasmant, E.; Sabbagh, A.; Masliah-Planchon, J.; Ortonne, N.; Laurendeau, I.; Melin, L.; Ferkal, S.; Hernandez, L.; Leroy, K.; Valeyrie-Allanore, L.; et al. Role of noncoding RNA ANRIL in genesis of plexiform neurofibromas in neurofibromatosis type 1. J. Natl. Cancer Inst. 2011, 103, 1713-1722.

65. Gschwendtner, A.; Bevan, S.; Cole, J.W.; Plourde, A.; Matarin, M.; Ross-Adams, H.; Meitinger, T.; Wichmann, E.; Mitchell, B.D.; Furie, K.; et al. Sequence variants on chromosome 9p21.3 confer risk for atherosclerotic stroke. Ann. Neurol. 2009, 65, 531-539.

66. Helgadottir, A.; Thorleifsson, G.; Manolescu, A.; Gretarsdottir, S.; Blondal, T.; Jonasdottir, A.; Jonasdottir, A.; Sigurdsson, A.; Baker, A.; Palsson, A.; et al. A common variant on chromosome 9p21 affects the risk of myocardial infarction. Science 2007, 316, 1491-1493.

67. Bos, J.L. Ras oncogenes in human cancer: A review. Cancer Res. 1989, 49, 4682.

68. Minamino, T.; Yoshida, T.; Tateno, K.; Miyauchi, H.; Zou, Y.; Toko, H.; Komuro, I. Ras induces vascular smooth muscle cell senescence and inflammation in human atherosclerosis. Circulation 2003, 108, 2264-2269.

69. Minamino, T.; Miyauchi, H.; Yoshida, T.; Ishida, Y.; Yoshida, H.; Komuro, I. Endothelial cell senescence in human atherosclerosis-Role of telomere in endothelial dysfunction. Circulation 2002, 105, 1541-1544.

70. Hirosue, A.; Ishihara, K.; Tokunaga, K.; Watanabe, T.; Saitoh, N.; Nakamoto, M.; Chandra, T.; Narita, M.; Shinohara, M.; Nakao, M. Quantitative assessment of higher-order chromatin structure of the INK4/ARF locus in human senescent cells. Aging Cell 2012, 11, 553-556.

71. Kim, W.Y.; Sharpless, N.E. The regulation of INK4/ARF in cancer and aging. Cell 2006, 127, 265-275. 
72. Krishnamurthy, J.; Torrice, C.; Ramsey, M.R.; Kovalev, G.I.; Al-Regaiey, K.; Su, L.; Sharpless, N.E. Ink4a/Arf expression is a biomarker of aging. J. Clin. Invest. 2004, 114, 1299-1307.

73. Li, H.; Collado, M.; Villasante, A.; Strati, K.; Ortega, S.; Cañamero, M.; Blasco, M.A.; Serrano, M. The Ink4/Arf locus is a barrier for iPS cell reprogramming. Nature 2009, 460, 1136-1139.

74. Krishnamurthy, J.; Ramsey, M.R.; Ligon, K.L.; Torrice, C.; Koh, A.; Bonner-Weir, S.; Sharpless, N.E. p16INK4a induces an age-dependent decline in islet regenerative potential. Nature 2006, 443, 453-457.

75. Molofsky, A.V.; Slutsky, S.G.; Joseph, N.M.; He, S.; Pardal, R.; Krishnamurthy, J.; Sharpless, N.E.; Morrison, S.J. Increasing p16INK4a expression decreases forebrain progenitors and neurogenesis during ageing. Nature 2006, 443, 448-452.

76. Mattick, J.S.; Makunin, I.V. Non-coding RNA. Hum. Mol. Genet. 2006, 15, R17-R29.

77. Bracken, A.P.; Dietrich, N.; Pasini, D.; Hansen, K.H.; Helin, K. Genome-wide mapping of Polycomb target genes unravels their roles in cell fate transitions. Genes Dev. 2006, 20, 1123-1136.

78. Ku, M.; Koche, R.P.; Rheinbay, E.; Mendenhall, E.M.; Endoh, M.; Mikkelsen, T.S.; Presser, A.; Nusbaum, C.; Xie, X.; Chi, A.S.; et al. Genomewide analysis of PRC1 and PRC2 occupancy identifies two classes of bivalent domains. PLoS Genet. 2008, 4, e1000242.

79. Kim, J.B.; Deluna, A.; Mungrue, I.N.; Vu, C.; Pouldar, D.; Civelek, M.; Orozco, L.; Wu, J.; Wang, X.; Charugundla, S.; et al. The effect of 9p21.3 coronary artery disease locus neighboring genes on atherosclerosis in mice. Circulation 2012, doi:10.1161/CIRCULATIONAHA.111.06488.

(C) 2013 by the authors; licensee MDPI, Basel, Switzerland. This article is an open access article distributed under the terms and conditions of the Creative Commons Attribution license (http://creativecommons.org/licenses/by/3.0/). 